\title{
Banana Fibers as Sorbent for Removal of Acid Green Dye from Water
}

\author{
Siti Kartina Abdul Karim, Soh Fong Lim, S. N. David Chua, \\ Shanti Faridah Salleh, and Puong Ling Law
}

Faculty of Engineering, Universiti Malaysia Sarawak, Kota Samarahan 94300, Malaysia

Correspondence should be addressed to Soh Fong Lim; sflim@unimas.my

Received 10 October 2016; Accepted 21 November 2016

Academic Editor: Wenshan Guo

Copyright (c) 2016 Siti Kartina Abdul Karim et al. This is an open access article distributed under the Creative Commons Attribution License, which permits unrestricted use, distribution, and reproduction in any medium, provided the original work is properly cited.

\begin{abstract}
In this study, banana fibers extracted from banana leaves, stem, and stalk were used to remove acid green dye from aqueous solution. Three initial concentrations $(750,1000$, and $1500 \mathrm{ppm})$ were chosen to determine the kinetic characteristics of the banana fiber sorbents at $25^{\circ} \mathrm{C}$, agitation speed of $200 \mathrm{rpm}$, and total contact time of 3 hours. The pseudo-first-order, pseudo-second-order, and Dunwald-Wagner kinetic models were applied to the experimental kinetic data. For isotherm study, the batch experiments were performed at $25^{\circ} \mathrm{C}$, initial $\mathrm{pH}$ 2, agitation speed of $200 \mathrm{rpm}$, and initial concentrations between 100 and $2000 \mathrm{ppm}$. The experimental data was fitted to the Langmuir, Freundlich, Dubinin-Radushkevich, and Temkin isotherms. The equilibrium was achieved in less than 90 minutes. The removal of the acid green dye was found to be following closely the pseudo-second-order kinetic model. For equilibrium study, the Freundlich isotherm was found to fit well with adsorption of acid green dye on the banana leaves, stem, and stalk sorbents. The calculated mean free energy of $4-11 \mathrm{~J} / \mathrm{mol}$ indicated that the sorption process was mostly physical in nature. Experimental results also showed the adsorption performance is greatly affected by the initial solution $\mathrm{pH}$.
\end{abstract}

\section{Introduction}

There are various industries that use dyes as colouring agents, such as textile, paint, pharmaceuticals, beauty products, and food. The release of dyes to water is harmful to the aquatic lives as most dyes are complex in nature and of synthetic origin [1]. Moreover, dyes hinder sunlight from entering water and slowing photosynthesis for plants in water [2]. Some of the techniques used to treat dye-containing wastewater are Fenton oxidation, membrane filtration, photodegradation, coagulation-flocculation, biosorption, and adsorption [3-10]. Ease of use, low energy application, and simple operation are some of the advantages of using membrane and coagulationflocculation [6, 7]. The drawbacks include searching for the right coagulants to maximize the process and membrane fouling. Chemical processes such as oxidation have high efficiency, though the high cost and disposal pose concern on the treatment process [11]. Adsorption is a physical process and has the advantages of simplicity, easy usage, and low energy consumption, similar to membrane and coagulationflocculation [12]. The use of natural fibers as sorbents is an attractive option, as it is biodegradable and low cost.

The use of natural fibers has been studied over a wide range of water pollutants. The sorbents are used in natural or unmodified form, as activated carbon, as biochar, or modified with other chemicals. Modification of natural fibers as activated carbon has been demonstrated using pineapple waste [2], where the surface area of activated carbon was higher than $500 \mathrm{~m}^{2} / \mathrm{g}$ and the maximum adsorption capacity was found to be $288 \mathrm{mg} / \mathrm{g}$ for adsorption of methylene blue. Biochar activated with microwave treatment was performed on $P$. juliflora species [13], where the surface area of adsorbents used was between 220 and $330 \mathrm{~m}^{2} / \mathrm{g}$, and the maximum adsorption capacity increased compared to the non-microwave-treated biochar. The use of unmodified and modified-by-calcination rice bran revealed that calcination at high temperature had an adverse effect on the adsorption capacity of the adsorbents [1]. Using methylene blue and 
crystal violet dyes as model compounds, the adsorption capacity for uncalcined and calcined rice bran decreased from 325.9 to $172.5 \mathrm{mg} / \mathrm{g}$ and from 783.8 to $401.3 \mathrm{mg} / \mathrm{g}$, respectively. The use of modification for natural fibers has to take into account the cost and environmental effects, as opposed to the increase (or decrease) in adsorption capacity.

Therefore, in this study, the natural form of banana is chosen as adsorbent. The banana plant used is taken from three parts of banana, which are the leaves, stem, and stalk. The three parts are used to remove acid green (AG) dye in aqueous solution.

\section{Materials and Methods}

2.1. Materials. The AG dye was purchased from Acros Organics. Analytical grade sodium hydroxide from Systerm (Malaysia) and 70.0\% nitric acid from J.T. Baker (USA) were used to adjust the $\mathrm{pH}$ of solution. The acid and base were prepared at a concentration of $0.1 \mathrm{M}$. The sorbents were prepared by using banana plants collected from Samarahan, Sarawak, Malaysia. The dye stock solution of 10000 ppm was prepared by adding $10 \mathrm{~g}$ of the AG dye powder in $1000 \mathrm{~mL}$ of deionised water. The stock solution was diluted to the desired AG dye concentrations for experimental usage.

2.2. Preparation of Banana Fiber Sorbents. Three different parts of banana plant were used to prepare the sorbents, which were the leaves, stem, and stalk. The plants were scraped and the fibers extracted from the different parts. Next, the extracted fibers were cut to about $2 \mathrm{~cm}$ before they were washed several times with deionised water. The drying took place next, with room temperature drying for three days and oven drying at $60^{\circ} \mathrm{C}$ for 24 hours. After drying, the banana parts were ground and sieved using 500-micron mesh size. The prepared sorbents were then stored in dry, airtight containers before use.

2.3. Batch Adsorption Experiments. In kinetic study, the experimental conditions were temperature at $25^{\circ} \mathrm{C}$, agitation speed of $200 \mathrm{rpm}$, adsorbent dosage of $60 \mathrm{~g} / \mathrm{L}$, and initial $\mathrm{pH}$ 2. The AG dye concentrations were varied at 750 , 1000 , and $1500 \mathrm{ppm}$. The experiments were carried out at predetermined experimental contact time, varying from 1 minute to 3 hours. After the predetermined contact time, the samples were filtered and the residual solutions were analysed using UV-Vis spectrophotometer (Thermo Scientific, model Evolution 201) at $624 \mathrm{~nm}$ of $\lambda_{\max }$.

Adsorption isotherm study for the batch adsorption experiments was conducted at $25^{\circ} \mathrm{C}$ with agitation speed of $200 \mathrm{rpm}$, adsorbent dosage of $60 \mathrm{~g} / \mathrm{L}$, contact time of 3 hours, and initial solution $\mathrm{pH}$ of approximately 2. The initial AG dye concentrations were varied from $100 \mathrm{ppm}$ to $2000 \mathrm{ppm}$. After 3 hours of experimental contact time, the samples were filtered and the residual solutions were analysed using the $\mathrm{UV}-\mathrm{Vis}$ spectrophotometer at $624 \mathrm{~nm}$ of $\lambda_{\max }$.

The solution $\mathrm{pH}$ effect study was performed for initial AG dye concentration of $1000 \mathrm{ppm}$ at operating temperature of $25^{\circ} \mathrm{C}$ with agitation speed of $200 \mathrm{rpm}$, adsorbent dosage of $60 \mathrm{~g} / \mathrm{L}$, and total experimental contact time of 3 hours. The initial solution $\mathrm{pH}$ was varied between 2 and 12 . After 3 hours of experimental contact time, the samples were filtered and the residual solutions were analysed using UVVis spectrophotometer (Thermo Scientific, model Evolution 201) at $624 \mathrm{~nm}$ of $\lambda_{\max }$.

Each batch experiment was carried out in duplicate and the average value was tabulated in graph form. The percentage removal was calculated using the following formula:

$$
\% \text { removal }=\frac{C_{0}-C_{t}}{C_{0}} \times 100 \%,
$$

where $C_{0}$ is the initial concentration and $C_{t}$ is the concentration at time interval.

The adsorption capacity, $Q$, was calculated using

$$
Q=\frac{\left(C_{0}-C_{t}\right) V}{m},
$$

where $C_{0}$ is the initial concentration, $C_{t}$ is the concentration at time interval, $V$ is the volume of solution used, and $m$ is the mass of sorbent.

2.4. Characterisation of the Sorbents. The sorbents were characterised using scanning electron microscopy (SEM) (JEOL Analytical Scanning Microscope, model JSM-6390LA) to visualise the surface morphologies of the sorbents and Fourier Transform Infrared (FT-IR) to analyse the surface functional groups of the sorbents. The FT-IR spectra were recorded using Shimadzu ASC 7000 Autosampler in the range of $400-4000 \mathrm{~cm}^{-1}$ with a resolution of $4 \mathrm{~cm}^{-1}$.

\section{Results and Discussion}

3.1. Kinetic Batch Experiments. The interaction between sorbent and sorbate is generally seen in the contact time needed to remove the sorbate from water. The adsorption capacities of the three banana sorbents at different contact time were illustrated in Figure 1. In general, the adsorption capacity increases rapidly in the first 15 minutes and then increases gradually when nearing the equilibrium stage before becoming near constant at equilibrium. The rapid increase in adsorption at the initial stage is due to the availability of sorption sites. As the sorption sites are filled, the sorption becomes slower and causes the smaller increase in adsorption capacity. At equilibrium, the sorption sites are fully occupied with sorbate or there is nearly no sorbate to interact with. At different initial concentrations, the adsorption capacity is seen to increase with the increase in initial concentration. This can be attributed to the higher concentration difference, which can provide stronger driving force. For banana leaves sorbent, the adsorption capacities at 750, 1000, and $1500 \mathrm{ppm}$ are $9.48,11.01$, and $18.40 \mathrm{mg} / \mathrm{g}$, respectively. Lower adsorption capacities are found for banana stem sorbent $(8.03,10.54$, and $17.02 \mathrm{mg} / \mathrm{g}$ ) and banana stalk sorbent $(7.28,10.39$, and $15.33 \mathrm{mg} / \mathrm{g}$ ). Furthermore, at higher initial concentrations, longer contact time is needed to achieve equilibrium as there are higher amount of sorbates. At 1500 ppm for banana leaves, 


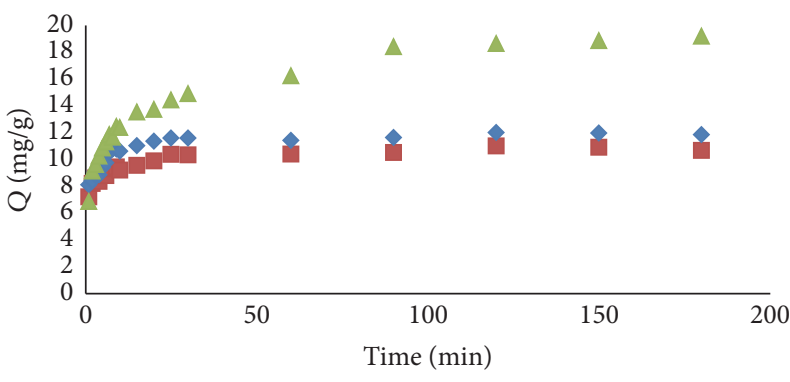

(a)

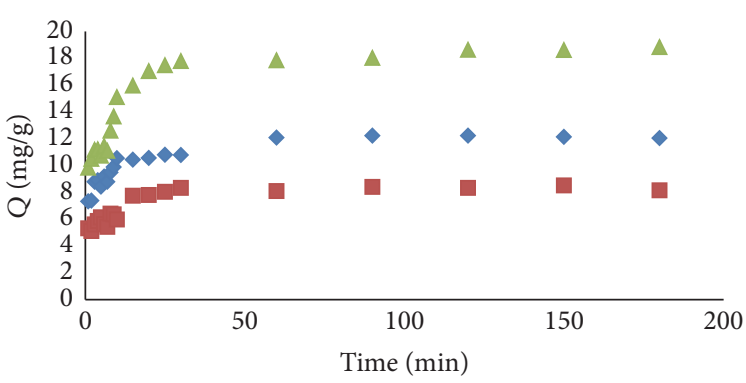

(b)

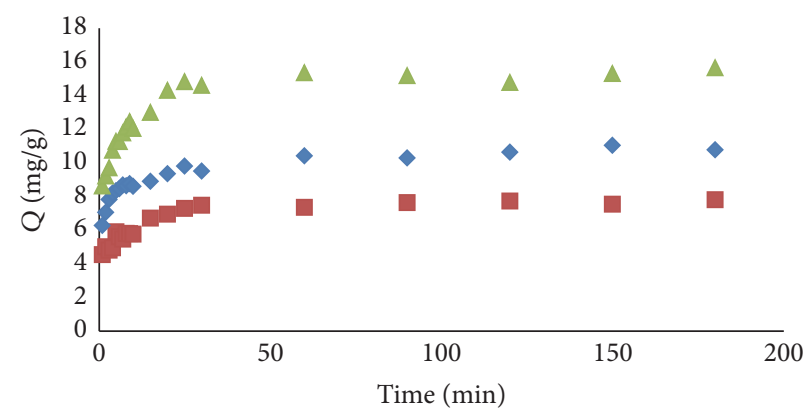

(c)

FIGURE 1: Adsorption capacity of (a) banana leaves sorbent, (b) banana stem sorbent, and (c) banana stalk sorbent for AG dye removal ( $750 \mathrm{ppm} ; 1000 \mathrm{ppm} ; 1500 \mathrm{ppm})$. Experimental conditions: temperature $=25^{\circ} \mathrm{C}$, agitation speed $=200 \mathrm{rpm}$, adsorbent dosage $=60 \mathrm{~g} / \mathrm{L}$, and initial $\mathrm{pH}=2$.

the equilibrium is achieved after 90 minutes, whereas the equilibrium is achieved after 25 minutes at $1000 \mathrm{ppm}$. Similar trend is exhibited with banana stem and banana stalk sorbents. At higher initial concentrations, there are more sorbate molecules to be sorbed. Therefore, longer time is needed to achieve the equilibrium state. Nevertheless, the sorption will be constant after equilibrium, indicating the saturation of sorption sites even with higher amount of sorbates. The equilibrium time for acid green dye was also found to be under 90 minutes using the Fenton method [5] and photodegradation with cobalt impregnated ZSM-5 catalyst [14].

3.2. The Effect of $p H$. Figure 2 shows the AG dye adsorption is greatly influenced by the acidic nature of solution. At highly acidic condition, with initial solution $\mathrm{pH}$ at approximately 2 , the banana leaves, stem, and stalk sorbents produce the highest adsorption capacity of $28.7 \mathrm{mg} / \mathrm{g}, 18.5 \mathrm{mg} / \mathrm{g}$, and $18.3 \mathrm{mg} / \mathrm{g}$, respectively. For banana leaves and stalk sorbents, the adsorption capacity decreases to a constant value over a large range of initial solution $\mathrm{pH}$ ( 3 to 11). It can be seen in Figure 3 that, for these two sorbents, the final solution $\mathrm{pH}$ is equilibrated at around 6 for initial $\mathrm{pH}$ between 3 and 11 , which explains why the adsorption capacity values became constant. For banana stem sorbent, the adsorption capacity is steadily decreasing as the solution $\mathrm{pH}$ increased. This could be due to the higher buffering value for this sorbent, which is at solution $\mathrm{pH}$ of 8 and 10 . As this solution $\mathrm{pH}$ is basic, it gives a negative effect to the AG dye adsorption using the banana stem sorbent. The solution $\mathrm{pH}$ influences the interaction between the surface of the sorbent and the adsorbate $[15,16]$.
The AG dye is an anionic dye, and highly positive surface charge at initial solution $\mathrm{pH} 2$ attracts the negative $\mathrm{SO}_{3}{ }^{-}$ functional group in the AG dye.

3.3. Adsorption Kinetics. The data from the kinetic experiments was further analysed and fitted to kinetic model equations. The best fit model was selected based on correlation of coefficients, where higher correlation gives the best fit model to the kinetic data. Several kinetic models were used to model the rate of adsorption of AG dye on banana leaves, stem, and stalk sorbents.

The pseudo-first-order kinetic equation describes adsorption rate based on adsorption capacities, where it assumes that one adsorbate molecule is adsorbed onto one active site [16]. The linear pseudo-first-order equation is given as

$$
\ln \left(q_{e}-q_{t}\right)=\ln q_{e}-k_{1} t
$$

where $q_{e}$ and $q_{t}$ are the adsorption capacity of sorbent $(\mathrm{mg} / \mathrm{g})$ at equilibrium and time $t$, respectively. The pseudo-first-order rate constants $k_{1}\left(\mathrm{~min}^{-1}\right)$ are determined from the slope of this equation.

Meanwhile, the pseudo-second-order equation is also used to describe adsorption rate based on adsorption capacities [17]. In this equation, one adsorbate molecule is assumed to be held onto two active sites. The linear form of this equation is given by

$$
\frac{t}{q_{t}}=\frac{1}{k_{2} q_{e}^{2}}+\frac{1}{q_{e}} t
$$




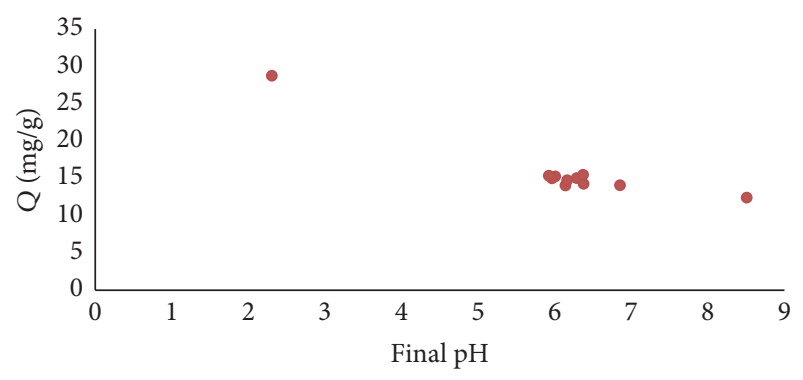

(a)

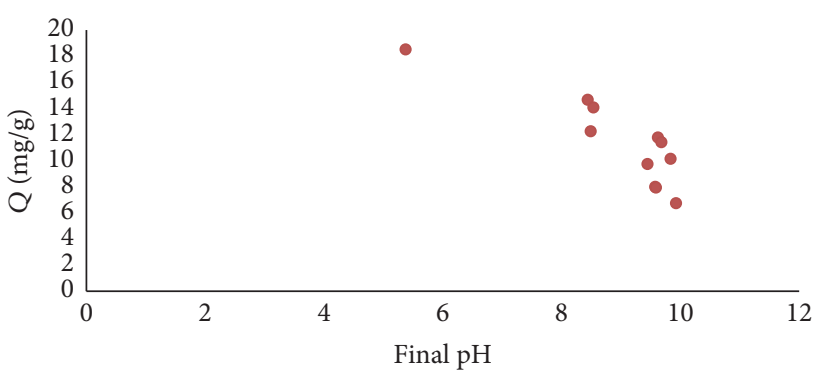

(b)

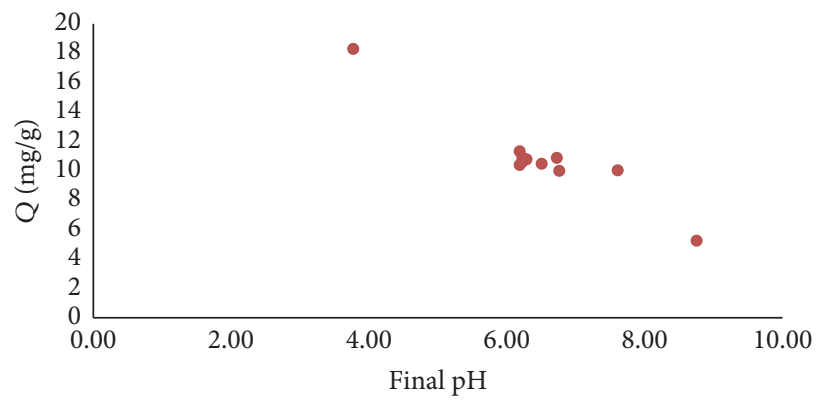

(c)

FIGURE 2: Adsorption capacity of (a) banana leaves sorbent, (b) banana stem sorbent, and (c) banana stalk sorbent for AG dye removal. Experimental conditions: temperature $=25^{\circ} \mathrm{C}$, agitation speed $=200 \mathrm{rpm}$, adsorbent dosage $=60 \mathrm{~g} / \mathrm{L}$, and initial concentration $=1000 \mathrm{ppm}$.

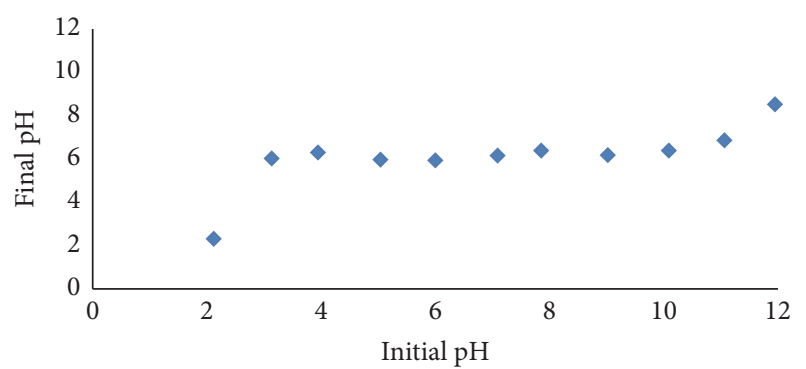

(a)

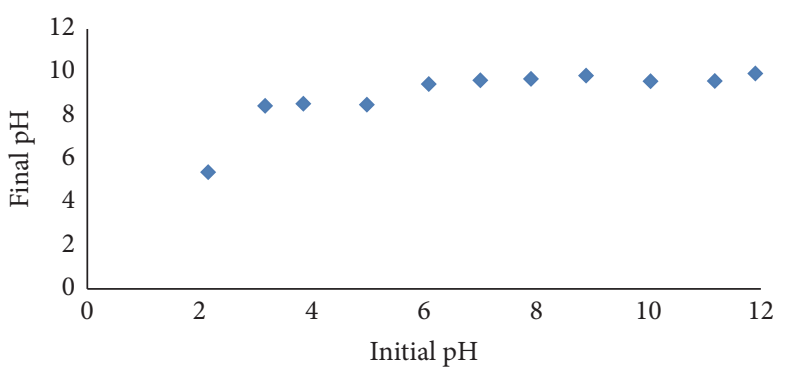

(b)

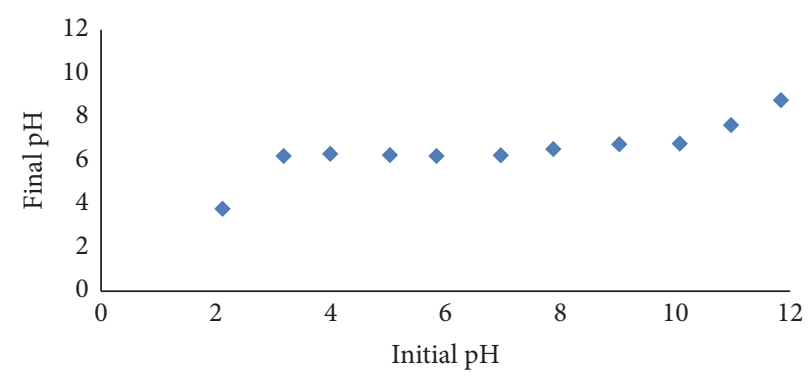

(c)

FIGURE 3: Initial versus final pH of (a) banana leaves sorbent, (b) banana stem sorbent, and (c) banana stalk sorbent for AG dye removal. Experimental conditions: temperature $=25^{\circ} \mathrm{C}$, agitation speed $=200 \mathrm{rpm}$, adsorbent dosage $=60 \mathrm{~g} / \mathrm{L}$, and initial concentration $=1000 \mathrm{ppm}$.

where $q_{e}$ and $q_{t}$ are the adsorption capacity of sorbent $(\mathrm{mg} / \mathrm{g}$ ) at equilibrium and time $t$, respectively. The pseudo-secondorder rate constants, $k_{2}(\mathrm{~g} / \mathrm{mg} \cdot \mathrm{min})$, are determined based on the slope of the equation.

The intraparticle diffusion model is used to explain the kinetics when pore diffusion is controlling the adsorption process. A common equation used to describe intraparticle diffusion is the Dunwald-Wagner equation:

$$
\log \left(1-\left(\frac{q_{t}}{q_{e}}\right)^{2}\right)=-k_{\mathrm{DW}} t
$$




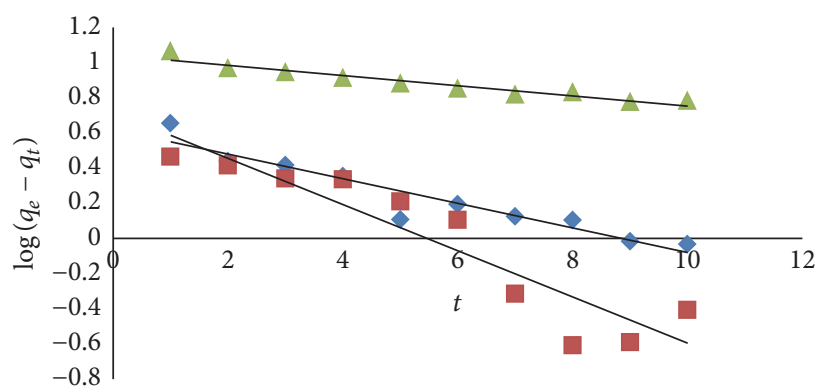

(a)

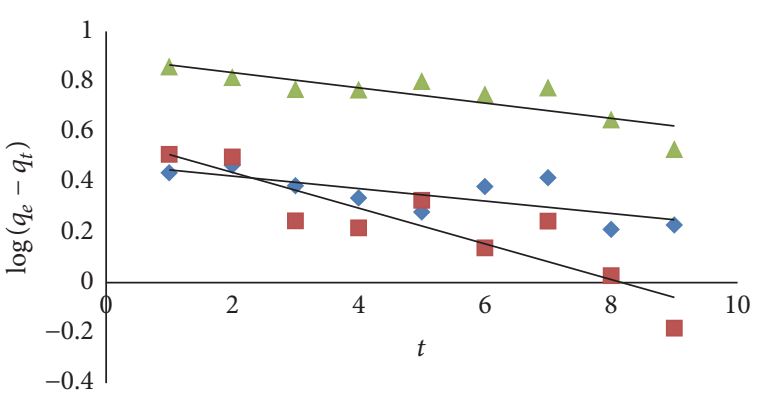

(b)

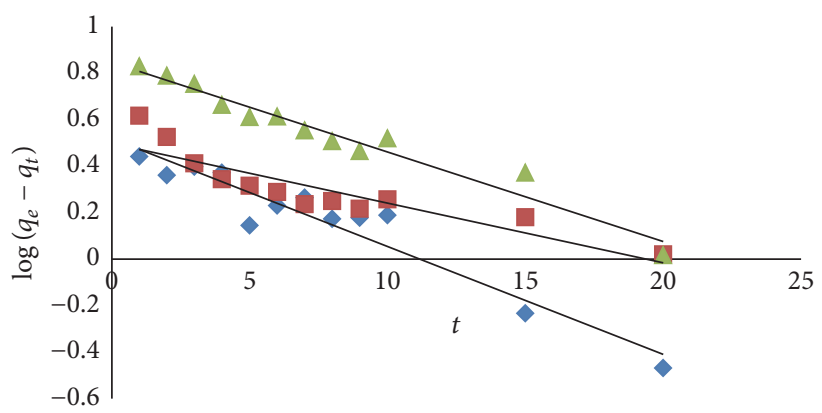

(c)

FIGURE 4: The pseudo-first-order plots for adsorption of AG dye on (a) banana leaves sorbent, (b) banana stem sorbent, and (c) banana stalk sorbent $(750 \mathrm{ppm} ; \mathbf{\square} 1000 \mathrm{ppm} ; \mathbf{\Delta} 1500 \mathrm{ppm})$.

TABLE 1: Adsorption kinetic parameters for banana stalk, stem, and leaves sorbents based on pseudo-first-order, pseudo-second-order, and intraparticle diffusion (Dunwald-Wagner) models.

\begin{tabular}{lcccccccccc}
\hline \multirow{2}{*}{ Sorbent } & \multirow{2}{*}{ Conc. $(\mathrm{mg} / \mathrm{L})$} & \multirow{2}{*}{$Q_{e, \text { exp }}(\mathrm{mg} / \mathrm{g})$} & \multicolumn{3}{c}{ Pseudo-first-order } & \multicolumn{3}{c}{ Pseudo-second-order } & \multicolumn{2}{c}{ Dunwald-Wagner } \\
& & & $k_{1}\left(\mathrm{~min}^{-1}\right)$ & $R^{2}$ & $Q_{e, \text { cal }}(\mathrm{mg} / \mathrm{g})$ & $k_{2}(\mathrm{~g} / \mathrm{mg} \cdot \mathrm{min})$ & $R^{2}$ & $Q_{e, \text { cal }}\left(\mathrm{mg}^{2} \mathrm{~g}\right)$ & $k_{\mathrm{DW}}\left(\mathrm{min}^{-1}\right)$ & $R^{2}$ \\
\hline \multirow{3}{*}{ Banana leaves } & 750 & 9.4752 & 0.1081 & 0.8724 & 3.1937 & $1.195 \times 10^{-3}$ & 0.9993 & 9.3985 & 0.09834 & 0.8937 \\
& 1000 & 11.0147 & 0.3026 & 0.8604 & 5.2204 & $5.430 \times 10^{-4}$ & 0.9924 & 11.5473 & 0.2867 & 0.8529 \\
& 1500 & 18.4032 & 0.02602 & 0.8936 & 8.5605 & $6.130 \times 10^{-4}$ & 0.9970 & 16.5837 & 0.2188 & 0.9308 \\
\hline \multirow{3}{*}{ Banana stem } & 750 & 8.0303 & 0.1382 & 0.8248 & 4.4066 & $3.492 \times 10^{-3}$ & 0.9657 & 8.1433 & 0.1283 & 0.8187 \\
& 1000 & 10.5425 & 0.1635 & 0.7976 & 3.8107 & $5.994 \times 10^{-4}$ & 0.9897 & 10.1215 & 0.1488 & 0.7922 \\
& 1500 & 17.0160 & 0.1350 & 0.8413 & 10.2612 & $4.118 \times 10^{-4}$ & 0.9471 & 16.8634 & 0.1198 & 0.8302 \\
\hline \multirow{3}{*}{ Banana stalk } & 750 & 7.2834 & 0.1069 & 0.9194 & 3.2984 & $4.127 \times 10^{-3}$ & 0.9865 & 7.2046 & 0.09742 & 0.9137 \\
& 1000 & 10.3923 & 0.05182 & 0.8444 & 2.9833 & $9.971 \times 10^{-4}$ & 0.9984 & 9.8328 & 0.04721 & 0.8558 \\
& 1500 & 15.3295 & 0.08590 & 0.9470 & 6.8328 & $5.152 \times 10^{-4}$ & 0.9957 & 15.4321 & 0.07853 & 0.9445 \\
\hline
\end{tabular}

The intraparticle diffusion equation will be crossing the origin if it is the only step that control the rate of adsorption $[18,19]$. The parameters involved in the kinetic equations and the regression coefficients $\left(R^{2}\right)$ are given in Table 1 .

The kinetics data fitted very well into the pseudo-secondorder model, with the correlation coefficient, $R^{2}$, of more than 0.94 for all three sorbents. This indicates that sorption of AG dye on banana stem, stalk, and leaves sorbents may be controlled by chemisorption, through sharing of valence forces or ion exchange. The pseudo-first-order kinetic equation has lower $R^{2}$ values than pseudo-second-order one, although the correlation is still considered good with $R^{2}>0.80$. The pseudo-first-order plots in Figure 4 show the nonlinearity of sorption using the three sorbents at 750 and $1000 \mathrm{ppm}$.
Moreover, calculated adsorption capacities using pseudofirst-order equation are not satisfactory in representing the experimental data compared to pseudo-second-order equation. Based on the pseudo-second-order plots in Figure 5, the experimental data conforms to the linear form of the equation well. The pseudo-second-order kinetics fits well with most systems of dye adsorption using natural fibers, such as adsorption of methylene blue and direct red using garlic straw [20,21], adsorption of crystal violet dye using sugarcane bagasse [11], removal of tartrazine using Lantana camara [22], crystal violet dye removal using papaya seed [23], and adsorption of navy blue using powdered orange [24]. Comprehensive review on pseudo-second-order model has demonstrated that this model is clearly advantageous in predicting adsorption of pollutants in aqueous solution, 


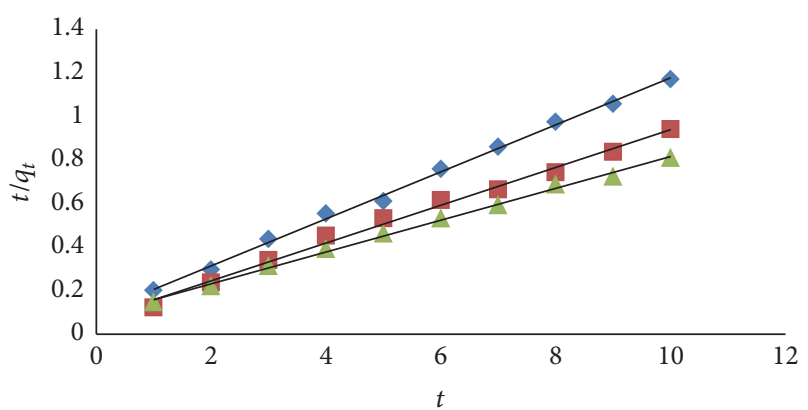

(a)

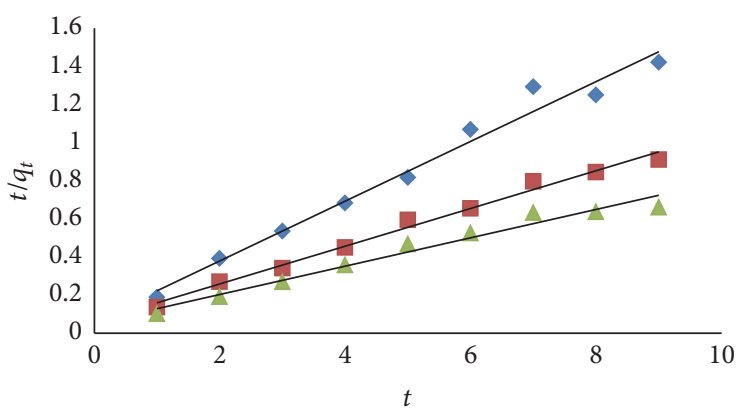

(b)

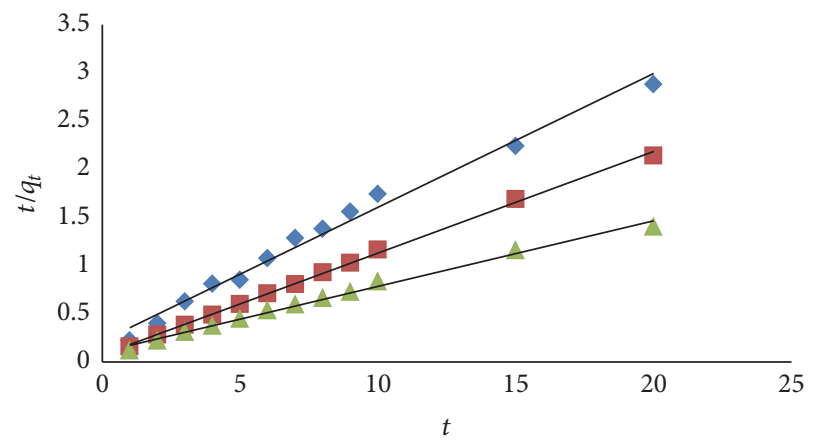

(c)

FIGURE 5: The pseudo-second-order plots for adsorption of AG dye on (a) banana leaves sorbent, (b) banana stem sorbent, and (c) banana stalk sorbent $(750 \mathrm{ppm}$; $1000 \mathrm{ppm} ; \mathbf{\Delta} 1500 \mathrm{ppm})$.

as there is no need to know the equilibrium capacity from the experiment, as it can be calculated from the model [25]. The intraparticle diffusion model has similar correlation coefficient values with pseudo-first-order model, with $R^{2}>$ 0.80 . Based on Figure 6 , the linear line for the equation does not cross the origin, indicating that the intraparticle diffusion is not the primary rate-controlling step.

3.4. Adsorption Isotherm. Four isotherm equations were chosen to represent the adsorption of AG dye onto banana stem, stalk, and leaves sorbents. The isotherm experiments data were fitted with four isotherm equations, namely, Langmuir, Freundlich, Dubinin-Radushkevich, and Temkin.

The assumptions of Langmuir isotherm were homogeneous adsorption sites, where a single layer of adsorption occurs $[26,27]$. Since the adsorption occurs in a monolayer, there are no further adsorption once the active site is occupied. The linear form of this model is written as

$$
\frac{C_{e}}{Q_{e}}=\frac{1}{Q_{m} K_{L}}+\frac{C_{e}}{Q_{m}}
$$

where $C_{e}$ is the equilibrium concentration $(\mathrm{mg} / \mathrm{L}), Q_{e}$ is the equilibrium adsorption capacity $(\mathrm{mg} / \mathrm{g}), Q_{m}$ is the maximum adsorption capacity $(\mathrm{mg} / \mathrm{g})$, and $K_{L}$ is the Langmuir isotherm constant $(\mathrm{L} / \mathrm{mg})$. An important dimensionless constant that can be extracted from Langmuir isotherm is called the separation factor, $R_{L} . R_{L}$ is a dimensionless constant that indicates whether the adsorption is favourable $\left(0<R_{L}<1\right)$, unfavourable $\left(R_{L}>1\right)$, linear $\left(R_{L}=1\right)$, or irreversible $\left(R_{L}=\right.$ $0) . R_{L}$ can be expressed as

$$
R_{L}=\frac{1}{1+K_{L} C_{0}} .
$$

On the other hand, the Freundlich isotherm model was more commonly applied to explain adsorption that occurs in multiple layers, and there is interaction between adsorbed molecules [2, 27]. Unlike the Langmuir model, the adsorption sites in Freundlich model were heterogeneous, with the adsorption energy that declines exponentially as it nears the adsorption centers. The $1 / n$ values indicate the degree of linearity of adsorption. When $1 / n$ value is between 0 and 1 , there exists some nonlinearity in the relationship between the solution concentration and adsorption. When $1 / n$ value is 1 , the adsorption is linear. The linear form of Freundlich isotherm is given as

$$
\ln Q_{e}=\ln K_{F}+\frac{1}{n} \ln C_{e},
$$

where $C_{e}$ is the equilibrium concentration $(\mathrm{mg} / \mathrm{L}), Q_{e}$ is the equilibrium adsorption capacity $(\mathrm{mg} / \mathrm{g}), K_{F}$ is the Freundlich isotherm constant $\left(\mathrm{mg}^{1-1 / n} \mathrm{~L}^{1 / n} \mathrm{~g}^{-1}\right)$, and $n$ is the adsorption intensity.

In order to calculate the apparent free energy of adsorption, the Dubinin-Radushkevich model can be used [27, 28]. The Dubinin-Radushkevich model is given by this linear equation:

$$
\ln Q_{e}=\ln Q_{m}-K_{\mathrm{DR}} \varepsilon^{2},
$$




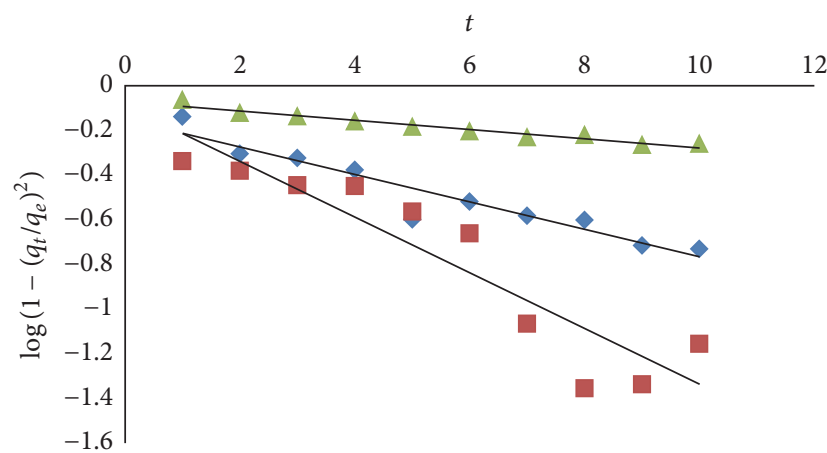

(a)

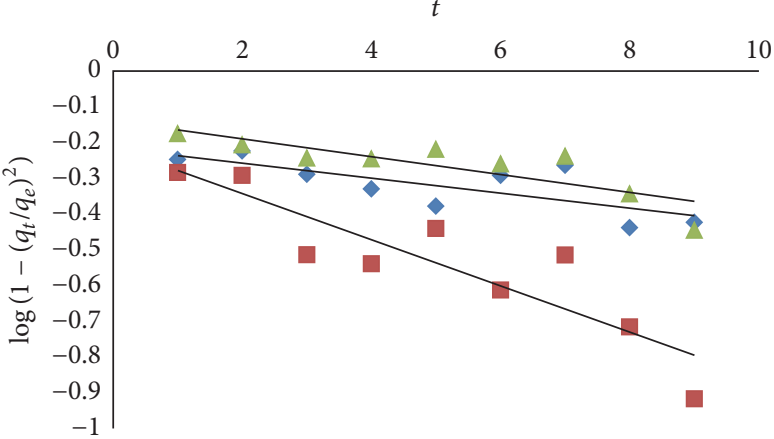

(b)

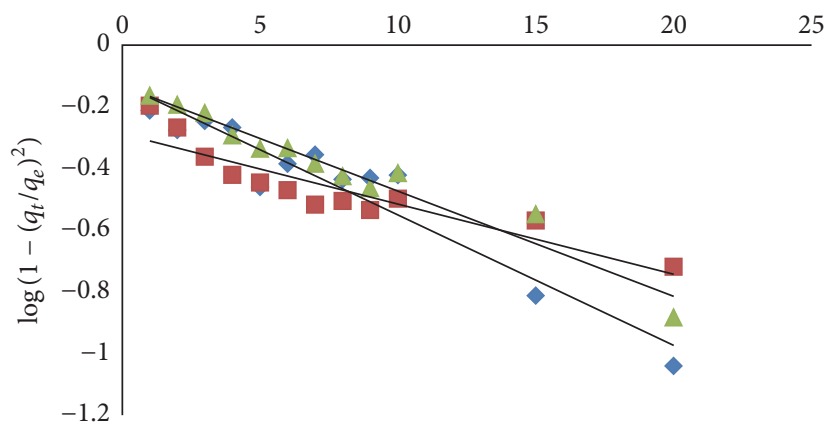

(c)

FiguRE 6: The intraparticle diffusion plots for adsorption of AG dye on (a) banana leaves sorbent, (b) banana stem sorbent, and (c) banana stalk sorbent ( 750 ppm; 1000 ppm; $\mathbf{\Delta} 1500$ ppm).

TABLE 2: Isotherm parameters for banana stalk, stem, and leaves sorbents based on Langmuir, Freundlich, Dubinin-Radushkevich, and Temkin models.

\begin{tabular}{lccccccccccc}
\hline & \multicolumn{3}{c}{ Langmuir } & \multicolumn{3}{c}{ Freundlich } & \multicolumn{3}{c}{ Dubinin-Radushkevich } & \multicolumn{2}{c}{ Temkin } \\
& $K_{L}$ & $R_{L}$ & $R^{2}$ & $K_{F}$ & $1 / n$ & $R^{2}$ & $K_{\mathrm{DR}}$ & $R^{2}$ & $A_{T}$ & $b_{T}$ & $R^{2}$ \\
\hline Banana leaves sorbent & 0.004508 & $0.09984-0.6893$ & 0.2721 & 0.4025 & 0.9263 & 0.8934 & 0.003644 & 0.8688 & 0.1320 & 274.5 & 0.8881 \\
Banana stem sorbent & 0.0002350 & $0.6802-0.9770$ & 0.6735 & 0.005716 & 1.484 & 0.9792 & 0.02380 & 0.8692 & 0.01968 & 218.7 & 0.7699 \\
Banana stalk sorbent & 0.003708 & $0.1188-0.7295$ & 0.6180 & 0.2654 & 0.8440 & 0.9079 & 0.004488 & 0.6996 & 0.07441 & 338.3 & 0.8407 \\
\hline
\end{tabular}

where $Q_{e}$ is the equilibrium adsorption capacity $(\mathrm{mg} / \mathrm{g})$, $Q_{m}$ is the saturation adsorption capacity $(\mathrm{mg} / \mathrm{g}), K_{\mathrm{DR}}$ is Dubinin-Radushkevich isotherm constant related to adsorption energy $\left(\mathrm{mol}^{2} / \mathrm{kJ}^{2}\right)$, and $\varepsilon$ is the Polanyi potential, which is defined as

$$
\varepsilon=R T \ln \left(1+\frac{1}{C_{e}}\right),
$$

where $R$ is the universal gas constant $(8.314 \mathrm{~J} / \mathrm{mol} \cdot \mathrm{K})$ and $T$ is the temperature in Kelvin.

Where the Freundlich isotherm assumes that the adsorption energy declines exponentially, the Temkin isotherm assumes that the heat of sorption declines linearly with temperature $[27,28]$ on the basis that the binding energies are uniformly distributed. The linear form of Temkin model is given as

$$
Q_{e}=\frac{R T}{B} \ln \left(A_{T}\right)+\frac{R T}{B} \ln \left(C_{e}\right)
$$

where $C_{e}$ is the equilibrium concentration $(\mathrm{mg} / \mathrm{L}), Q_{e}$ is the equilibrium adsorption capacity $(\mathrm{mg} / \mathrm{g}), R$ is the universal gas constant $(8.314 \mathrm{~J} / \mathrm{mol} \cdot \mathrm{K}), T$ is the temperature in Kelvin, $A_{T}$ is the Temkin isotherm equilibrium binding constant $(\mathrm{L} / \mathrm{mg})$, and $B$ is defined as

$$
B=\frac{R T}{b_{T}},
$$

where $b_{T}$ is the Temkin isotherm constant.

The parameters associated with adsorption isotherm models above are given in Table 2. For all three sorbents, the Freundlich isotherm model is the best fitting isotherm, with $R^{2}$ of 0.8934 for banana leaves sorbent, 0.9792 for banana stem sorbent, and 0.9079 for banana stalk sorbent. This points to multilayer adsorption with interaction between adsorbed AG dye molecules. The isotherm is in line with kinetics, where the tendency for pseudo-second-order model indicates the interaction of one dye molecule to two adsorption sites. The three sorbents performed the worst for Langmuir 


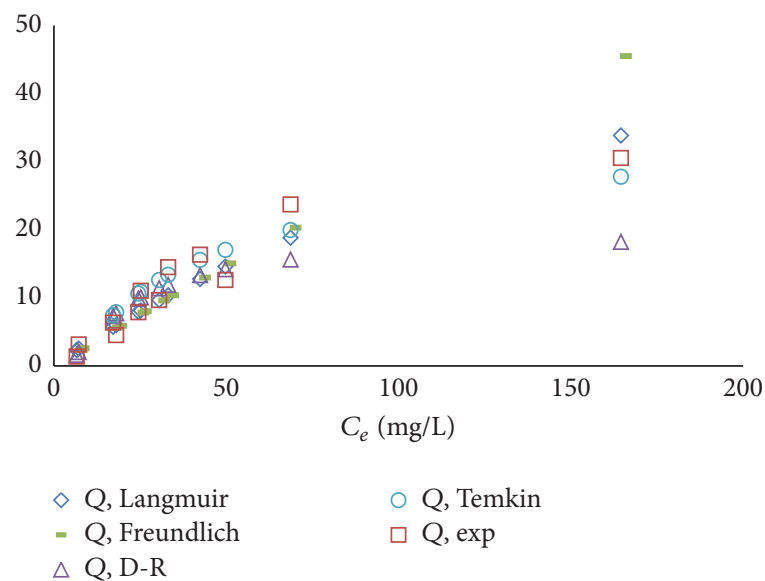

(a)

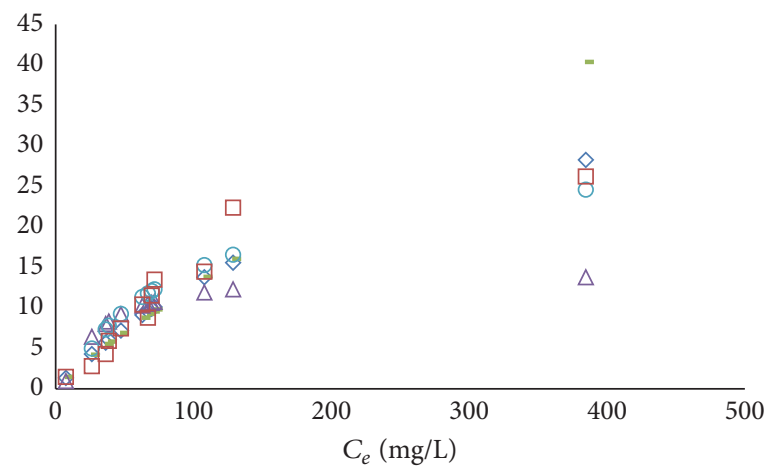

$\diamond$ Q, Langmuir
$=$ Q, Freundlich
$\Delta$ Q, D-R

Q, Temkin

$\square \mathrm{Q}, \exp$

(c)

(b)

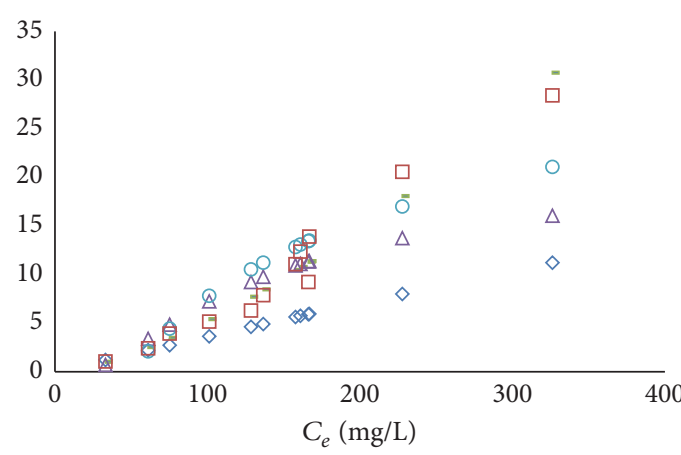

$\diamond Q$, Langmuir $\quad \circ Q$, Temkin

- Q, Freundlich $\quad \square Q$, exp

$\triangle \mathrm{Q}, \mathrm{D}-\mathrm{R}$

FIGURE 7: Experimental and calculated adsorption capacity of (a) banana leaves sorbent, (b) banana stem sorbent, and (c) banana stalk sorbent for $\mathrm{CV}$ dye removal. Experimental conditions: temperature $=25^{\circ} \mathrm{C}$, agitation speed $=200 \mathrm{rpm}$, adsorbent dosage $=60 \mathrm{~g} / \mathrm{L}$, and initial $\mathrm{pH}=2$.

isotherm model, with $R^{2}$ of less than 0.68 . Nonetheless, the separation factor calculated using this model is between 0 and 1 for all three sorbents, showing that the adsorption is favourable under the conditions used. The maximum adsorption capacities calculated using Langmuir model are $79.36 \mathrm{mg} / \mathrm{g}$ for banana leaves sorbent, $157.73 \mathrm{mg} / \mathrm{g}$ for banana stem sorbent, and $48.08 \mathrm{mg} / \mathrm{g}$ using banana stalk sorbent. The Dubinin-Radushkevich isotherm fits satisfactorily for banana leaves and banana stem sorbent, with $R^{2}$ of 0.8688 and 0.8692 , respectively. Using this model, the apparent free adsorption energy for each sorbent is calculated. The banana leaves sorbent has the highest free energy of $11.71 \mathrm{~J} / \mathrm{mol}$, the banana stalk sorbent is the next with $10.56 \mathrm{~J} / \mathrm{mol}$, and the banana stem sorbent has the lowest energy at $4.58 \mathrm{~J} / \mathrm{mol}$. All these energy values are very low, indicating physisorption nature of adsorption, as it is lower than $8.0 \mathrm{~kJ} / \mathrm{mol}$ [29]. The experimental and calculated adsorption capacities were presented in Figure 7. The calculated adsorption capacities were close to the experimental ones at $C_{e}$ lower than $100 \mathrm{mg} / \mathrm{L}$. At higher equilibrium concentrations, the calculated adsorption capacities were closely represented by using Langmuir and
Temkin isotherms for banana leaves and stalk sorbents and by using Freundlich for banana stem sorbents.

3.5. Characterisation. The micrographs of SEM in Figure 8 show the surface morphologies of the sorbent after adsorption of the AG dye. The fibrillar structure in banana can be seen in the banana leaves, stem, and stalk sorbents, as has been reported in literature [30-32]. The stem and stalk sorbents are more homogeneous in structure, with smooth surface, compared to banana leaves sorbent. After the adsorption process, the AG dye molecules seem to cover part of the surface of the sorbents, as can be seen in Figures $8(\mathrm{a})-8$ (c) for the adsorption using $750 \mathrm{ppm}$ of the AG dye and Figures $8(\mathrm{~d})-8(\mathrm{f})$ for the adsorption using $1000 \mathrm{ppm}$ of the AG dye. Similar morphologies were also found for the adsorption using $1500 \mathrm{ppm}$ of the AG dye (not shown). The AG dye molecules were seen on the surface and inside the cavities of the sorbents.

FT-IR spectra after adsorption of the AG dye for the banana leaves, stem, and stalk sorbents are given in Figure 9. The surface functional groups found in the banana leaves, 


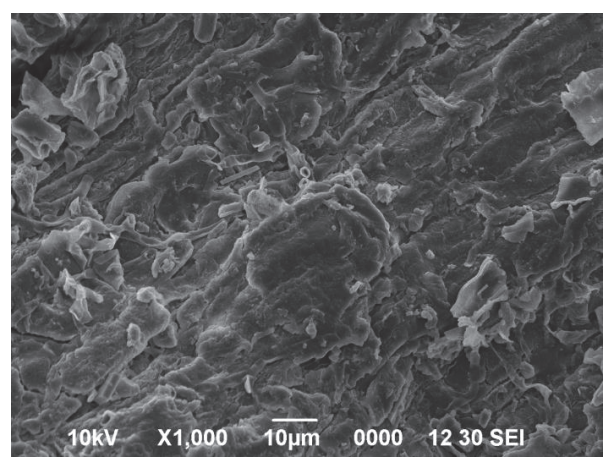

(a)

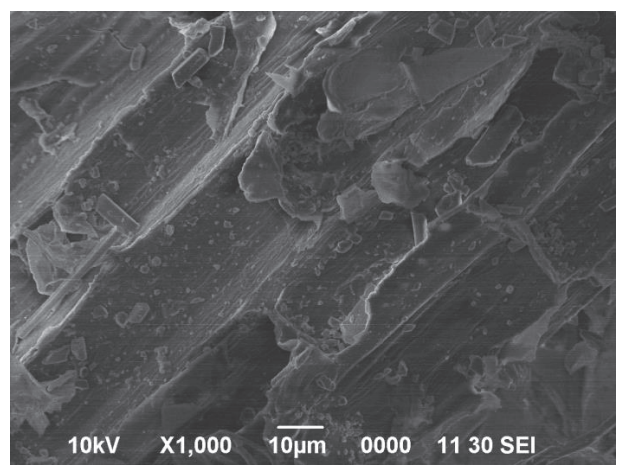

(c)

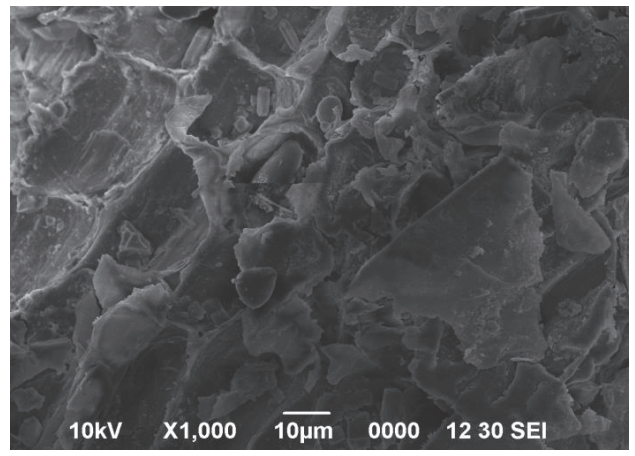

(e)

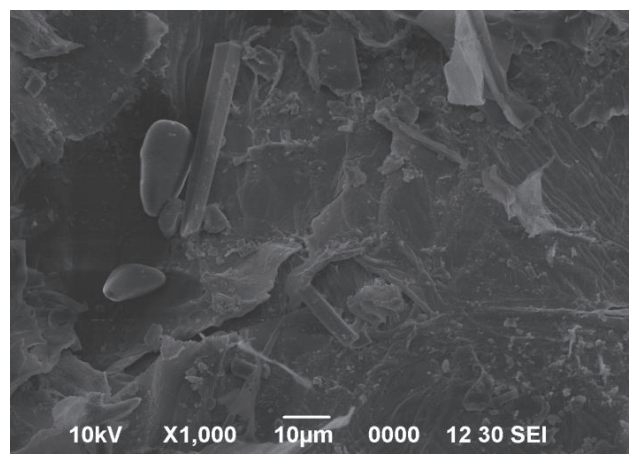

(b)

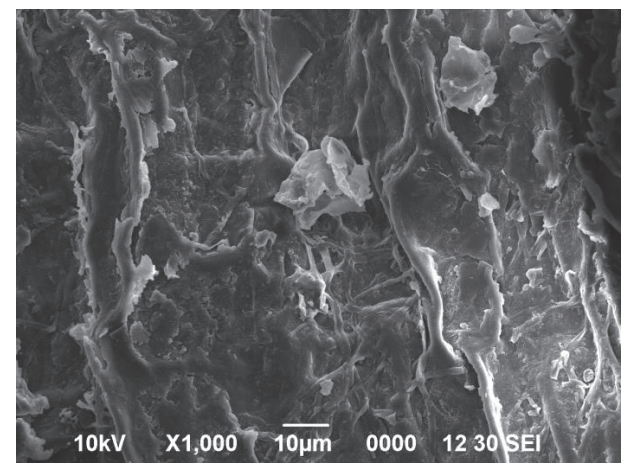

(d)

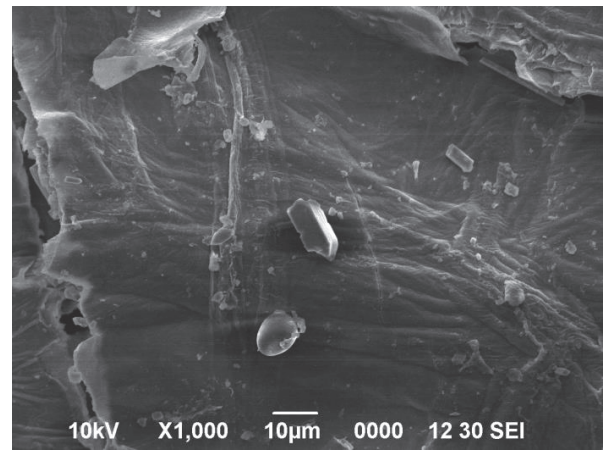

(f)

FIGURE 8: SEM images for (a) banana leaves sorbent, (b) banana stem sorbent, and (c) banana stalk sorbent, after adsorption using 750 ppm of AG dye, and (d) banana leaves sorbent, (e) banana stem sorbent, and (f) banana stalk sorbent, after adsorption using 1000 ppm of AG dye.

stem, and stalk sorbents are hydroxyl group at around $3400 \mathrm{~cm}^{-1}, \mathrm{CH}_{2}$ symmetric stretching at around $2900 \mathrm{~cm}^{-1}$, overlapping peaks between 1600 and $1250 \mathrm{~cm}^{-1}$ for $\mathrm{C}-\mathrm{C}, \mathrm{C}=\mathrm{C}$, $\mathrm{OH}, \mathrm{CO}, \mathrm{CH}_{n}$, and C-O-C commonly found in polysaccharides, peak at around $1050 \mathrm{~cm}^{-1}$ for $\mathrm{C}-\mathrm{O}$ in alcohol group, and peaks between 550 and $430 \mathrm{~cm}^{-1}$ for deformations of C$\mathrm{H}$ groups in aromatic linkages, as described in our previous work [33]. The functional groups detected in AG dye (inset of Figure 9) are very similar to the ones in the sorbents used; thus, the FT-IR of the banana leaves, stem, and stalk sorbents remain the same after the adsorption. As can be seen, the peaks for functional groups at $3400 \mathrm{~cm}^{-1}, 2900 \mathrm{~cm}^{-1}, 1600$ $1250 \mathrm{~cm}^{-1}, 1050 \mathrm{~cm}^{-1}$, and 550 to $430 \mathrm{~cm}^{-1}$ are unshifted for all sorbents after the adsorption. Only the intensity of the hydroxyl group becomes less at concentration of $1500 \mathrm{ppm}$, though the peaks remain unshifted. This could indicate that the adsorption of these sorbents is more physical than chemical, as the functional groups are not strongly affected after adsorption took place.

\section{Conclusions}

The batch kinetics study for AG dye using banana leaves, stem, and stalk sorbents showed that the adsorption capacity for removal of AG dye is between 8 and $18 \mathrm{mg} / \mathrm{g}$ across all three concentrations used. The adsorption capacity increases with the increase in initial concentration in the range of concentrations tested. Sorption capacities of AG dye on 


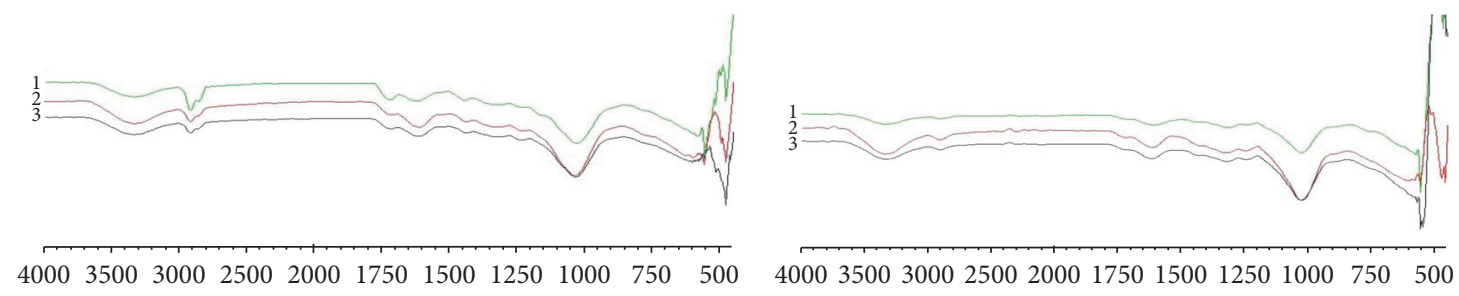

(a)

(b)

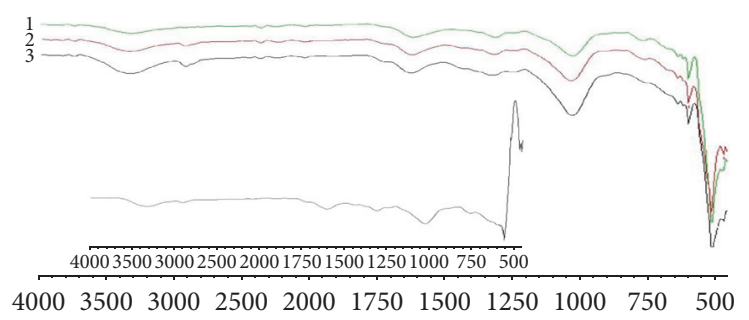

(c)

FIGURE 9: FT-IR spectra for (a) banana leaves sorbent, (b) banana stem sorbent, and (c) banana stalk sorbent, at (1) 1500 ppm, (2) 1000 ppm, and (3) $750 \mathrm{ppm}$. The inset in (c) is the FT-IR spectrum for AG dye.

banana leaves, stem, and stalk sorbents are higher at very low $\mathrm{pH}$ (initial $\mathrm{pH}=2$ ), whereas at higher $\mathrm{pH}$ the sorption capacities do not vary much, due to the buffering effect.

The sorption of all three sorbents follows closely pseudosecond-order kinetics, suggesting chemisorption involved as rate-controlling step. However, calculated mean free energy (using Dubinin-Radushkevich model) showed that the adsorption produces energy of less than $12 \mathrm{~J} / \mathrm{mol}$, which is much lower than chemisorption energy of $8 \mathrm{~kJ} / \mathrm{mol}$. The intraparticle diffusion model shows good conformity to the data, but all linear lines do not pass through origin, indicating that this is not the sole rate-limiting step. The adsorption of AG dye using banana stalk, stem, and leaves sorbents was found to fit into the Freundlich isotherm, suggesting multilayer adsorption.

\section{Competing Interests}

The authors declare that there is no conflict of interests regarding the publication of this paper.

\section{Acknowledgments}

The authors would like to thank Universiti Malaysia Sarawak for the use of laboratory facilities and equipment.

\section{References}

[1] F. Ogata, D. Imai, and N. Kawasaki, "Cationic dye removal from aqueous solution by waste biomass produced from calcination treatment of rice bran," Journal of Environmental Chemical Engineering, vol. 3, no. 3, pp. 1476-1485, 2015.

[2] M. N. Mahamad, M. A. A. Zaini, and Z. A. Zakaria, "Preparation and characterization of activated carbon from pineapple waste biomass for dye removal," International Biodeterioration \& Biodegradation, vol. 102, pp. 274-280, 2015.
[3] S. Wang, Y. Guan, L. Wang et al., "Fabrication of a novel bifunctional material of $\mathrm{BiOI} / \mathrm{Ag}_{3} \mathrm{VO}_{4}$ with high adsorptionphotocatalysis for efficient treatment of dye wastewater," Applied Catalysis B: Environmental, vol. 168-169, pp. 448-457, 2015.

[4] A. Siddiqa, D. Masih, D. Anjum, and M. Siddiq, "Cobalt and sulfur co-doped nano-size $\mathrm{TiO}_{2}$ for photodegradation of various dyes and phenol," Journal of Environmental Sciences, vol. 37, pp. 100-109, 2015.

[5] R. J. Ramírez, C. A. P. Arellano, A. A. Á. Gallegos, A. E. J. González, and S. S. Martínez, " $\mathrm{H}_{2} \mathrm{O}_{2}$-assisted $\mathrm{TiO}_{2}$ generation during the photoelectrocatalytic process to decompose the acid green textile dye by Fenton reaction," Journal of Photochemistry and Photobiology A: Chemistry, vol. 305, pp. 51-59, 2015.

[6] N. A. Oladoja, "Headway on natural polymeric coagulants in water and wastewater treatment operations," Journal of Water Process Engineering, vol. 6, pp. 174-192, 2015.

[7] M. R. S. Kebria, M. Jahanshahi, and A. Rahimpour, "SiO2 modified polyethyleneimine-based nanofiltration membranes for dye removal from aqueous and organic solutions," Desalination, vol. 367, pp. 255-264, 2015.

[8] P. Sun, C. Hui, S. Wang, L. Wan, X. Zhang, and Y. Zhao, "Bacillus amyloliquefaciens biofilm as a novel biosorbent for the removal of crystal violet from solution," Colloids and Surfaces B: Biointerfaces, vol. 139, pp. 164-170, 2016.

[9] A. Masoumi, K. Hemmati, and M. Ghaemy, "Low-cost nanoparticles sorbent from modified rice husk and a copolymer for efficient removal of $\mathrm{Pb}(\mathrm{II})$ and crystal violet from water," Chemosphere, vol. 146, pp. 253-262, 2016.

[10] T. Sarat Chandra, S. N. Mudliar, S. Vidyashankar et al., "Defatted algal biomass as a non-conventional low-cost adsorbent: surface characterization and methylene blue adsorption characteristics," Bioresource Technology, vol. 184, pp. 395-404, 2015.

[11] B. C. S. Ferreira, F. S. Teodoro, A. B. Mageste, L. F. Gil, R. P. de Freitas, and L. V. A. Gurgel, "Application of a new carboxylatefunctionalized sugarcane bagasse for adsorptive removal of crystal violet from aqueous solution: kinetic, equilibrium and thermodynamic studies," Industrial Crops and Products, vol. 65, no. 1, pp. 521-534, 2015. 
[12] A. Bhatnagar, M. Sillanpää, and A. Witek-Krowiak, "Agricultural waste peels as versatile biomass for water purificationa review," Chemical Engineering Journal, vol. 270, pp. 244-271, 2015.

[13] V. Nair and R. Vinu, "Peroxide-assisted microwave activation of pyrolysis char for adsorption of dyes from wastewater," Bioresource Technology, vol. 216, pp. 511-519, 2016.

[14] Z. M. El-Bahy, M. M. Mohamed, F. I. Zidan, and M. S. Thabet, "Photo-degradation of acid green dye over Co-ZSM-5 catalysts prepared by incipient wetness impregnation technique," Journal of Hazardous Materials, vol. 153, no. 1-2, pp. 364-371, 2008.

[15] J. Zolgharnein, M. Bagtash, and T. Shariatmanesh, "Simultaneous removal of binary mixture of Brilliant Green and Crystal Violet using derivative spectrophotometric determination, multivariate optimization and adsorption characterization of dyes on surfactant modified nano- $\gamma$-alumina," Spectrochimica Acta Part A: Molecular and Biomolecular Spectroscopy, vol. 137, pp. 1016-1028, 2015.

[16] T. A. Khan, E. A. Khan, and Shahjahan, "Removal of basic dyes from aqueous solution by adsorption onto binary ironmanganese oxide coated kaolinite: non-linear isotherm and kinetics modeling," Applied Clay Science, vol. 107, pp. 70-77, 2015.

[17] Y. S. Ho and G. McKay, "Pseudo-second order model for sorption processes," Process Biochemistry, vol. 34, no. 5, pp. 451$465,1999$.

[18] H. Qiu, L. Lv, B.-C. Pan, Q.-J. Zhang, W.-M. Zhang, and Q.-X. Zhang, "Critical review in adsorption kinetic models," Journal of Zhejiang University: Science A, vol. 10, no. 5, pp. 716-724, 2009.

[19] S.-F. Lim and A. Y. W. Lee, "Kinetic study on removal of heavy metal ions from aqueous solution by using soil," Environmental Science and Pollution Research, vol. 22, no. 13, pp. 10144-10158, 2015.

[20] F. Kallel, F. Chaari, F. Bouaziz, F. Bettaieb, R. Ghorbel, and S. E. Chaabouni, "Sorption and desorption characteristics for the removal of a toxic dye, methylene blue from aqueous solution by a low cost agricultural by-product," Journal of Molecular Liquids, vol. 219, pp. 279-288, 2016.

[21] F. Kallel, F. Bouaziz, F. Chaari, L. Belghith, R. Ghorbel, and S. E. Chaabouni, "Interactive effect of garlic straw on the sorption and desorption of Direct Red 80 from aqueous solution," Process Safety and Environmental Protection, vol. 102, pp. 30-43, 2016.

[22] R. K. Gautam, P. K. Gautam, S. Banerjee et al., "Removal of tartrazine by activated carbon biosorbents of Lantana camara: kinetics, equilibrium modeling and spectroscopic analysis," Journal of Environmental Chemical Engineering, vol. 3, no. 1, pp. 79-88, 2015.

[23] F. A. Pavan, E. S. Camacho, E. C. Lima, G. L. Dotto, V. T. A. Branco, and S. L. P. Dias, "Formosa papaya seed powder (FPSP): preparation, characterization and application as an alternative adsorbent for the removal of crystal violet from aqueous phase," Journal of Environmental Chemical Engineering, vol. 2, no. 1, pp. 230-238, 2014.

[24] S. Irem, Q. Mahmood Khan, E. Islam et al., "Enhanced removal of reactive navy blue dye using powdered orange waste," Ecological Engineering, vol. 58, pp. 399-405, 2013.

[25] Y.-S. Ho, "Review of second-order models for adsorption systems," Journal of Hazardous Materials, vol. 136, no. 3, pp. 681689, 2006.

[26] T. S. Anirudhan and M. Ramachandran, "Adsorptive removal of basic dyes from aqueous solutions by surfactant modified bentonite clay (organoclay): kinetic and competitive adsorption isotherm," Process Safety and Environmental Protection, vol. 95, pp. 215-225, 2015.

[27] S. Rangabhashiyam, N. Anu, M. S. Giri Nandagopal, and N. Selvaraju, "Relevance of isotherm models in biosorption of pollutants by agricultural byproducts," Journal of Environmental Chemical Engineering, vol. 2, no. 1, pp. 398-414, 2014.

[28] A. O. Dada, A. P. Olalekan, A. M. Olatunya, and O. Dada, "Langmuir, freundlich, temkin and dubinin-radushkevich isotherms studies of equilibrium sorption of $\mathrm{Zn}^{2+}$ unto phosphoric acid modified rice husk," IOSR Journal of Applied Chemistry, vol. 3, no. 1, pp. 38-45, 2012.

[29] P. C. N. Ejikeme, E. M. Ejikeme, and G. N. Okonkwo, "Equilibrium, kinetic and thermodynamic studies on basic dye adsorption using composite activated carbon," International Journal of Technical Research and Applications, vol. 2, pp. 96103, 2014

[30] H. Becker, R. F. Matos, J. A. D. Souza, D. D. A. Lima, F. T. C. D. Souza, and E. Longhinotti, "Pseudo-stem banana fibers: characterization and chromium removal," Orbital, vol. 5, no. 3, 2013.

[31] S. S. Pillai, B. Deepa, E. Abraham et al., "Biosorption of Cd(II) from aqueous solution using xanthated nano banana cellulose: equilibrium and kinetic studies," Ecotoxicology and Environmental Safety, vol. 98, pp. 352-360, 2013.

[32] R. R. Mohammed and M. F. Chong, "Treatment and decolorization of biologically treated Palm Oil Mill Effluent (POME) using banana peel as novel biosorbent," Journal of Environmental Management, vol. 132, pp. 237-249, 2014.

[33] S. K. A. Karim and S.-F. Lim, "Removal of lead(II) ions in water using banana fiber," Australian Journal of Basic and Applied Sciences, vol. 9, pp. 62-66, 2015. 

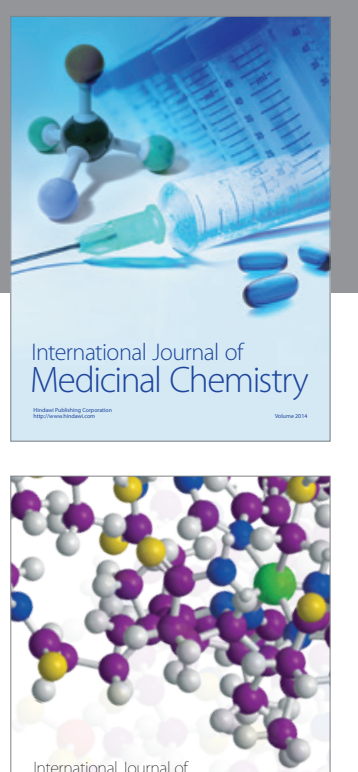

Carbohydrate Chemistry

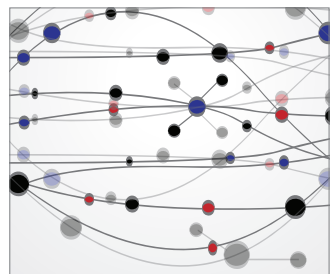

The Scientific World Journal
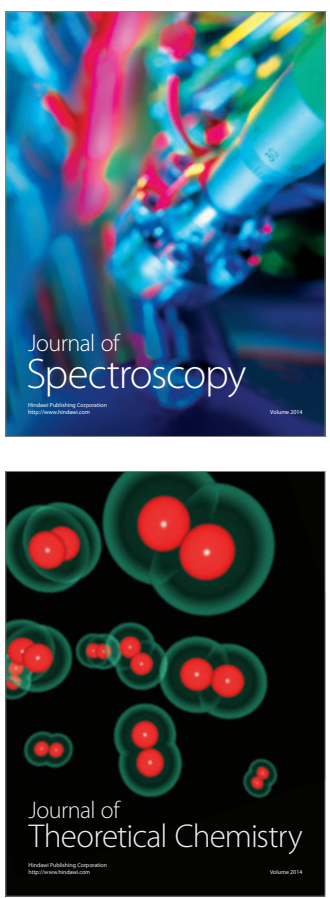
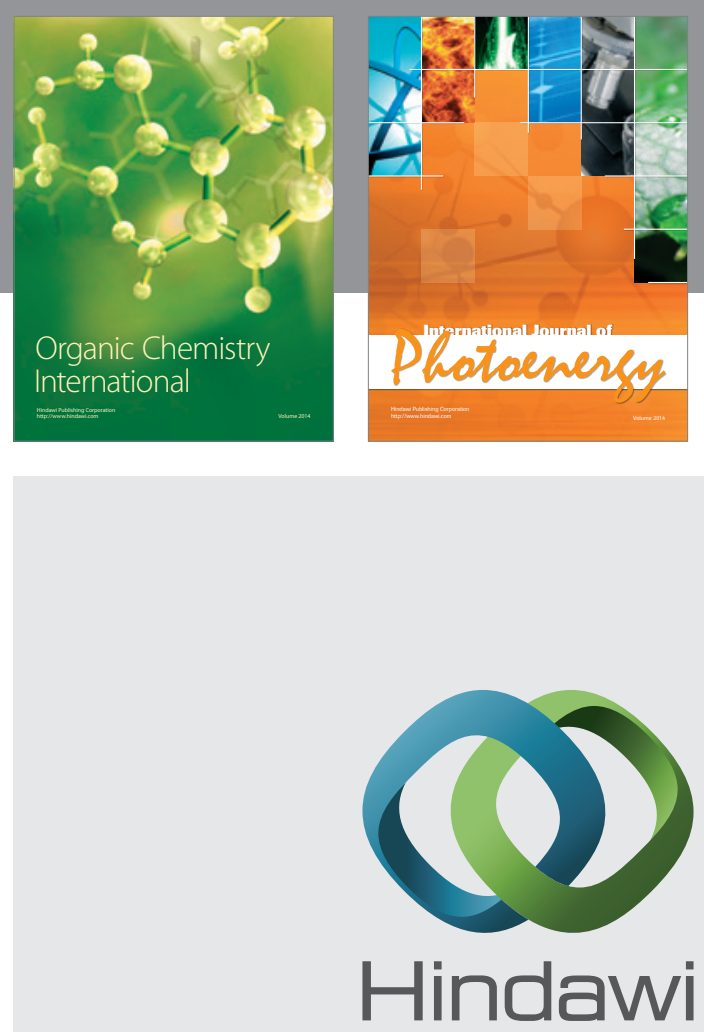

Submit your manuscripts at

http://www.hindawi.com

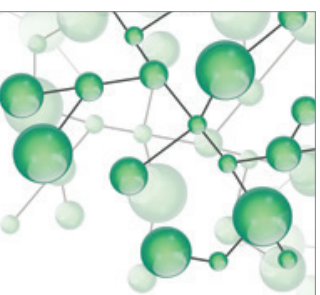

International Journal of

Inorganic Chemistry

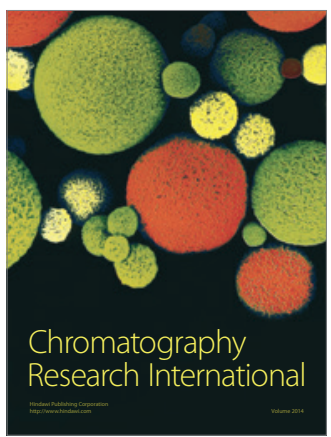

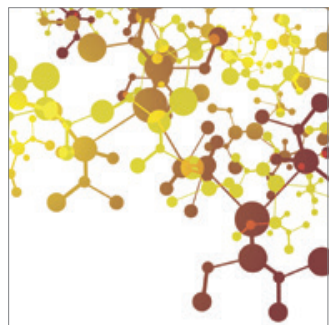

Applied Chemistry
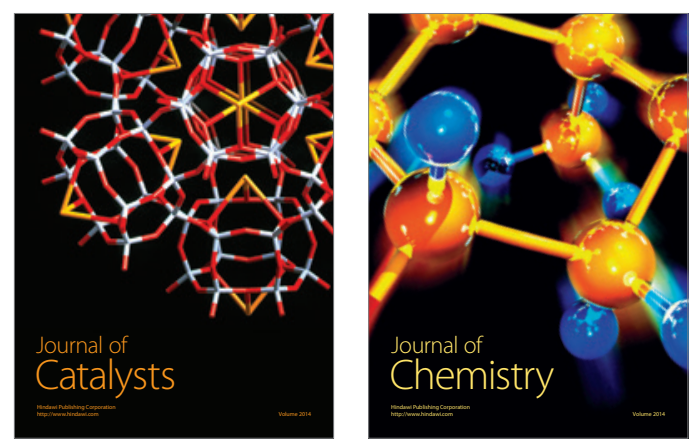
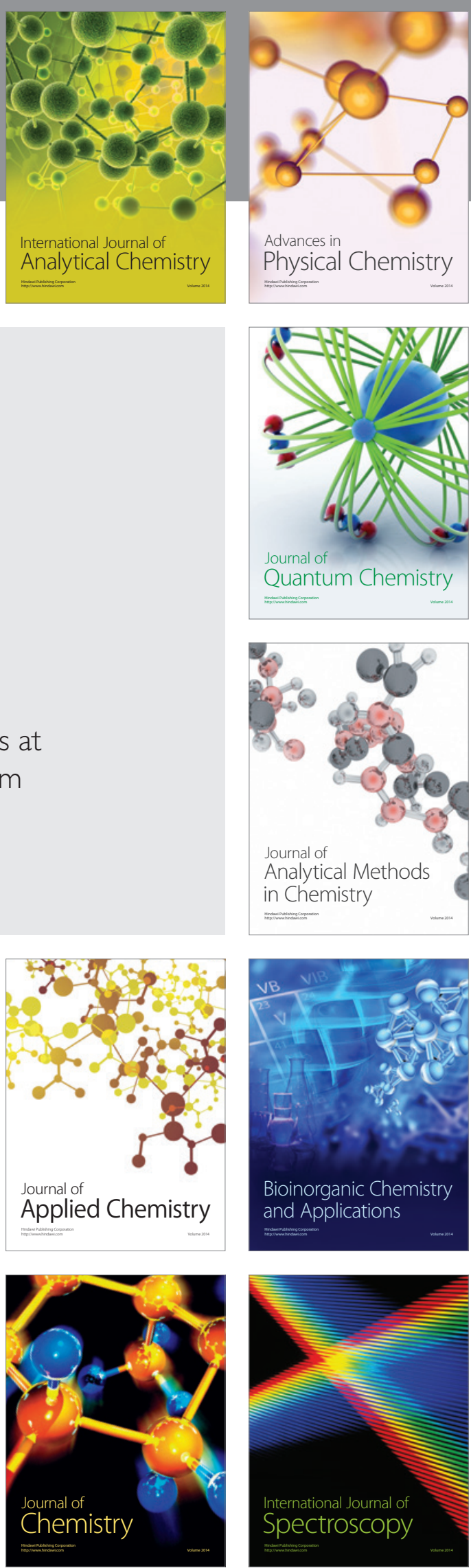